\title{
PRODUTIVIDADE DA ALFACE AMERICANA COM DIFERENTES COMPOSIÇÕES DE ADUBAÇÃO QUÍMICA E ORGÂNICA EM FUNÇÃO DO TEOR DE NITROGÊNIO
}

Fernando Bernardo Martins ${ }^{1}$, Thadeu Henrique Novais Spósito ${ }^{2}$, Luis Eduardo Vieira Pinto ${ }^{1}$, Alline Mendes Alves ${ }^{1}$, Lorrayne Guimarães Bavaresco ${ }^{1}$, Rodrigo Bernardo Soldá ${ }^{3}$, Felipe Silva Loosli ${ }^{1}$, Patrícia Rafaella de Mello ${ }^{1}$, Wilton Felipe Teixeira ${ }^{1}$

\footnotetext{
${ }^{1}$ Universidade do Oeste Paulista - UNOESTE, Programa de Pós-Graduação em Agronomia, Presidente Prudente, SP.

2Universidade Estadual Paulista "Júlio de Mesquita Filho", Programa de Pós-Graduação em Agronomia, Ilha Solteira, SP.

${ }^{3}$ Universidade do Oeste Paulista - UNOESTE, Programa de Residência Agronômica, Presidente Prudente, SP. E-mail: fernixbr@gmail.com
}

\section{RESUMO}

O nitrogênio $(N)$ é um elemento essencial para as plantas sendo, de maneira geral, o nutriente mais exigido pelas culturas, para a alface, o nitrogênio é considerado o segundo elemento químico de maior extração pela planta. O experimento foi conduzido na área experimental da ETEC (Colégio Agrícola) de Presidente Prudente/SP. Utilizou-se um delineamento experimental de blocos casualizados, contendo 4 tratamentos (adubação), com 5 repetições. Os tratamentos utilizados foram baseados na aplicação de $90 \mathrm{~kg}$ de nitrogênio por hectare para o plantio de alface, levando em consideração o teor de nitrogênio de cada material de acordo com Raij (1997), sendo estes: T1 (Testemunha), T2 (Ureia (20 gramas por $\mathrm{m}^{2}$ )), T3 (Esterco bovino curtido (600 gramas por $\left.\mathrm{m}^{2}\right)$ ) e T4 (Composto orgânico (1000 gramas por $\left.\mathrm{m}^{2}\right)$ ), o que resultaria na aplicação de 9 gramas de nitrogênio por metro quadrado. A utilização de adubação orgânica promoveu maior ganho de massa total da alface.

Palavras-chave: Ureia. Esterco Bovino. Composto Orgânico. Agroecologia. Olericultura.

\section{AMERICAN LETTUCE PRODUCTIVITY WITH DIFFERENT CHEMICAL AND ORGANIC FERTILIZER COMPOSITIONS IN THE FUNCTION OF NITROGEN CONTENT}

\begin{abstract}
Nitrogen $(\mathrm{N})$ is an essential element for plants and is generally the nutrient most demanded by crops. For lettuce, nitrogen is considered the second chemical element of greatest extraction by the plant. The experiment was conducted in the experimental area of the ETEC (Agricultural College) of Presidente Prudente / SP. A randomized complete block design with 4 treatments (fertilization) was used, with 5 replicates. The treatments used were based on the application of $90 \mathrm{~kg}$ of nitrogen per hectare for lettuce planting, taking into account the nitrogen content of each material according to Raij (1997), being: T1 (Witness), T2 (Urea 20 grams per m2), T3 (tanned bovine manure (600 grams per $\mathrm{m} 2$ )) and T4 (Organic compound (1000 grams per m2)), which would result in the application of 9 grams of nitrogen per square meter. The use of organic fertilization promoted greater total lettuce mass gain.
\end{abstract}

Keywords: Urea. Bovine Stuffing. Organic compost. Agroecology. Olericultura.

\section{INTRODUÇÃO}

Atualmente o consumo de hortaliças tem aumentado devido a maior conscientização da população em busca de uma dieta alimentar mais rica e saudável. Desse modo, o desenvolvimento 
de sistemas de cultivo de hortaliças, com vistas à otimização da produtividade, tem exigido dos agricultores esforços no sentido de reduzir ou até mesmo eliminar as deficiências do setor produtivo (MONTEZANO e PEIL, 2006). As hortaliças são alimentos importantes, pois são fontes de micronutrientes, fibras e de outros componentes com propriedades funcionais, são alimentos de baixa densidade energética, isto é, com poucas calorias em relação ao volume da alimentação consumida, o que favorece a manutenção do peso corporal saudável (VAN DUYN e PIVONKA, 2000).

A alface (Lactuca sativa L.) é a hortaliça folhosa de maior importância no Brasil (COSTA e SALA, 2005) sendo esta a hortaliça mais consumida no país. Segundo Carvalho et al. (2013), a produção brasileira de alface é de aproximadamente 1,3 milhões de toneladas por ano, sendo a região Sudeste responsável por $70 \%$ do total produzido. As espécies mais cultivadas são: crespa, lisa, americana, mimosa e romana sendo a crespa a que o brasileiro mais consome. Bem adaptada ao clima brasileiro pode ser cultivada o ano todo.

A alface é uma planta é herbácea, delicada, com caule diminuto, ao qual se prendem as folhas. Estas são amplas e crescem em roseta, em volta do caule, podendo ser lisas ou crespas, formando ou não uma cabeça, com coloração em vários tons de verde, ou roxa, conforme a cultivar, e são essas características que determinam à preferência do consumidor (FILGUEIRA, 2003). O solo ideal para o cultivo dessa hortaliça é o de textura média, rico em matéria orgânica e com boa disponibilidade de nutrientes. Para se obter maior produtividade, é necessário o uso de insumos que melhorem as condições físicas, químicas e biológicas do solo (SOUZA et al., 2005).

A adubação orgânica com esterco de animais e compostos orgânicos tem sido amplamente utilizada na produção de alface e tem como objetivo reduzir as quantidades de fertilizantes químicos e melhorar as qualidades físicas, químicas e biológicas do solo (PEIXOTO FILHO et al., 2013).

O uso do esterco bovino na adubação apresenta benefícios que vão além do fornecimento de nutrientes, uma vez que ele pode influenciar de forma positiva a dinâmica da MO, podendo aumentar o teor de carbono orgânico do solo e diminuir a emissão de gases para a atmosfera (LOSS et al., 2011). Diversos estudos têm demonstrado os efeitos benéficos do uso do esterco bovino na qualidade do solo após vários anos de aplicação (BRITO et al., 2005; MELO et al., 2011). Como fonte de $\mathrm{MO}$, o uso de esterco auxilia na formação e estabilização dos agregados, melhorando a porosidade, reduzindo a densidade do solo, aumentando a macroporosidade e a taxa de infiltração de água (MELLEK et al., 2010).

O composto orgânico é o material obtido da compostagem, possui cor escura, é rico em húmus e contém de $50 \%$ a $70 \%$ de matéria orgânica. É classificado como adubo orgânico, pois é preparado a partir de estercos de animais e/ou restos de vegetais que, em estado natural, não têm valor agrícola. Recebe esse nome pela forma como é preparado, montando-se pilhas compostas de diferentes camadas de materiais orgânicos. A composição do composto orgânico, depende da natureza da matéria prima utilizada. Entende-se, desde já, que o benefício da matéria orgânica no solo não é apenas o de fornecedor de nutrientes para as plantas, mas, principalmente, de modificador, para melhorar suas propriedades físicas e biológicas (LIMA et al., 2004).

A compostagem é uma das maneiras de aproveitar melhor os resíduos orgânicos, através deste processo há um aumento de temperatura provocada pela atividade de microrganismos termófilos, contribuindo para a redução de patógenos e sementes de plantas daninhas (GRASSI FILHO, et. al. 2017). A compostagem refere-se ao processo de decomposição controlada da matéria orgânica por microrganismos, transformando-a em um material humificado de cor escura, odor de terra e benéfico ao solo e as plantas (BRITO et al., 2009). Para Freitas et al. (2009) a utilização de compostos orgânicos reduz em $30 \%$ a adubação química. 
O emprego de fertilizantes minerais em alface é uma prática agrícola que traz resultados satisfatórios em termos de produtividade (SOUZA et al., 2005). Sendo a alface uma cultura composta basicamente por folhas, esta responde muito à adubação nitrogenada. $A$ adubação nitrogenada é um dos principais fatores que afetam a produtividade e a qualidade da alface. A falta ou doses baixas de nitrogênio acarretam menor produção, doses excessivas podem diminuir o rendimento e afetar a qualidade nutritiva, além de resultar em desperdício de fertilizantes (FERREIRA, 2002).

Esse experimento teve como objetivo avaliar a produtividade da alface americana cultivada em vasos em diferentes composições de adubos, químico e orgânicos.

\section{METODOLOGIA}

O experimento foi conduzido na área experimental da ETEC - Escola Técnica Professor Dr. Antonio Eufrásio de Toledo (Colégio Agrícola) de Presidente Prudente/SP, localizada a $22^{\circ} 07^{\prime} 32^{\prime \prime}$ de latitude, $51^{\circ} 23^{\prime} 20^{\prime \prime}$ de longitude e $475 \mathrm{~m}$ de altitude, durante o período de setembro a novembro de 2016. O clima da região se classifica em Aw, com estação chuvosa no verão e estação seca no inverno. Utilizou-se um delineamento experimental de blocos casualizados, contendo 4 tratamentos (adubação), com 5 repetições. Os tratamentos utilizados foram baseados na aplicação de $90 \mathrm{~kg}$ de nitrogênio por hectare para o plantio de alface, levando em consideração o teor de nitrogênio de cada material de acordo com Raij (1997), sendo estes: T1 (Testemunha), T2 (Ureia (20 gramas por $\left.\mathrm{m}^{2}\right)$ ), T3 (Esterco bovino curtido (600 gramas por $\mathrm{m}^{2}$ )) e T4 (Composto orgânico (1000 gramas por $\left.\mathrm{m}^{2}\right)$ ), o que resultaria na aplicação de 9 gramas de nitrogênio por metro quadrado.

As mudas da alface cultivar Lucy Brown, foram adquiridas na casa agropecuária DEFEMA de Pirapozinho, SP no dia 19 de setembro de 2016. Neste mesmo dia foi realizado o plantio em jardineiras, estas foram preparadas com pedra no fundo para drenagem da água e terra de barranco (terra de subsolo) já incorporados com os materiais de cada tratamento. A irrigação foi realizada 2 vezes por dia, exceto em dias chuvosos, proporcionando a mesma quantidade de água para todas as plantas. No dia 31 de outubro de 2016, as plantas foram colhidas, limpas, divididas em fração raiz e parte aérea para posterior pesagem em balança digital de precisão no Laboratório da escola. Todos os dados foram submetidos à análise de variância (ANOVA, $p<0,05)$ e ao teste de comparação de médias Scott-Knott $(p<0,05)$, segundo Silva (2011).

\section{RESULTADOS}

Atualmente o consumo de hortaliças tem aumentado devido a maior conscientização da população em busca de uma dieta alimentar mais rica e saudável. Desse modo, o desenvolvimento de sistemas de cultivo com hortaliças, com vistas à otimização da produtividade, tem exigido dos agricultores esforços no sentido de reduzir ou até mesmo eliminar as deficiências do setor produtivo (MONTEZANO e PEIL, 2006).

A partir dos resultados obtidos na tabela 01, observa-se que a utilização de adubação derivada de resíduos orgânicos promoveu maior ganho de massa total da alface durante o período de execução do ensaio. 
Tabela 1. Resultados de análises estatísticas das variáveis analisadas "Comprimento da Raiz (C.R.), Comprimento da Parte Aérea (C.P.A.), Massa Seca da Raiz (M.S.R.) e Massa Seca da Parte Aérea (M.S.P.A.) " em relação aos substratos utilizados no experimento.

\begin{tabular}{cccc}
\hline TRATAMENTOS & MASSA PARTE AÉREA $(\mathrm{g})$ & MASSA RAIZ $(\mathrm{g})$ & MASSA TOTAL $(\mathrm{g})$ \\
\hline T1 & $12,54 \mathrm{~b}$ & $1,91 \mathrm{a}$ & $14,47 \mathrm{~b}$ \\
T2 & $13,73 \mathrm{~b}$ & $3,13 \mathrm{a}$ & $16,87 \mathrm{~b}$ \\
T3 & $21,18 \mathrm{a}$ & $2,57 \mathrm{a}$ & $25,46 \mathrm{a}$ \\
T4 & $18,84 \mathrm{a}$ & $3,40 \mathrm{a}$ & $22,24 \mathrm{a}$ \\
\hline CV (\%) & 24,43 & 30,68 & 23,26 \\
\hline
\end{tabular}

Médias seguidas por letras iguais na coluna não diferem entre si pelo teste de Scott-Knott a 5\%.

\section{DISCUSSÃO}

Nota-se que para o desenvolvimento do sistema radicular das plantas não houve diferença estatística significativa em relação aos diferentes tratamentos utilizados no experimento. Quando avaliado a massa da parte aérea e a massa total das plantas, verificou-se um incremento de peso nas plantas onde foram submetidas a adubação com o esterco bovino curtido (T3) e o composto orgânico (T4), ambos estatisticamente iguais para todas as variáveis.

De acordo com Silva et al. (2011), a adubação orgânica não só incrementa a produtividade, mas também produz plantas com características qualitativas melhores que as cultivadas exclusivamente com adubos minerais podendo, portanto, exercer influência sobre a qualidade nutricional da alface. Além disso, a matéria orgânica influencia positivamente em diversas características do solo, tais como: aumento da população de microrganismos, disponibiliza nutrientes para a cultura, melhora a CTC (capacidade de troca catiônica), complexa elementos tóxicos e micronutrientes, participa na formação de agregados do solo e, consequentemente, diminui a densidade do solo, aumenta a porosidade, infiltração, retenção de água e aeração (LUCHESE et al., 2002; SOUZA; RESENDE, 2006).

A adubação orgânica segundo Leite et al., (2003) aumenta os estoques de carbono orgânico e $\mathrm{N}$ total no solo, em relação aos sistemas de produção com adubação mineral ou mesmo sem adubação, o que posiciona como uma estratégia de manejo importante à conservação da fertilidade do solo. A incorporação de material orgânico no solo, além de fornecer nutrientes como N, P, K e S, influência as propriedades físicas do solo, reduzindo a densidade aparente, formando agregados, melhorando a aeração e a capacidade de armazenamento de água (KIEHL, 1985). Segundo o autor, os adubos orgânicos têm, também, efeito sobre o poder tampão do solo ao manter o pH quando há mudanças bruscas no meio, além de favorecer a troca catiônica, complexar e solubilizar alguns metais tóxicos às plantas e ter influência na temperatura do solo. Outros efeitos, segundo Costa (1994), são o de favorecer o enraizamento, diminuir os efeitos tóxicos do Al e aumentar a atividade microbiana do solo.

\section{CONCLUSÃO}

O uso da adubação orgânica promoveu maior desenvolvimento da parte aérea da planta, fator importante comercialmente, porém não influenciou no desenvolvimento do sistema radicular quando comparado com a adubação mineral e o tratamento testemunha.

\section{REFERÊNCIAS BIBLIOGRÁFICAS}

BRITO, L. M.; AMARO, A. L.; FERNANDES, A. S. Revista de Ciencias Agrarias, Lisboa, v. 32, n. 1, p. 298-311, 2009. 
BRITO, O. R.; VENDRAME, P. R. S; BRITO, R. M. Alterações das propriedades químicas de um Latossolo vermelho distroférrico submetido a tratamentos com resíduos orgânicos, Semina, v.26, n.1, p. 33-40, 2005. https://doi.org/10.5433/1679-0359.2005v26n1p33

CARVALHO, C. Anuário Brasileiro de hortaliças. Santa Cruz: Gazeta Santa Cruz, 2013.

COSTA, C.P; SALA, F.C. A evolução da alfacicultura brasileira. Horticultura Brasileira, 23: 820-824, 2005.

COSTA, M. B. B. da. Adubação orgânica: nova síntese e novo caminho para a agricultura. São Paulo: Ícone, 1994. 102p.

FERREIRA, V. P. Doses e parcelamento de nitrogênio em alface. 2002. 56 f. Dissertação (Mestrado em Fitotecnia) - Universidade Federal do Rio Grande do Sul, Porto Alegre, 2002.FILGUEIRA, F. A. R. Novo manual de olericultura: agrotecnologia moderna na produção e comercialização de hortaliças. 2a ed., UFV, 2003.

FREITAS, M. E.; BONO, J. A. M.; PEDRINHO, D. R.; CHERMOUTH, K. da S.; YAMAMOTO, C. R.; VIDIS, R. Y. DE. Utilização de composto orgânico para adubação na cultura da alface. AGRARIAN, v. 2, n. 3, p. 41-52, 2009.

GRASSI FILHO, Helio et al. Eficiência do manejo do nitrogênio químico e orgânico irrigado com água residuária na alface. Environmental Research Science \& Technology, v. 1, n. 1, p. 43-55, 2017.

KIEHL, E.J. Fertilizantes orgânicos. São Paulo: Ceres, 1985. 492p

LEITE, L.F.C.; MENDONÇA, E.S.; NEVES, J.C.L.; MACHADO, P.L.O.A.; GALVÃO, J. C.C. Estoques totais de carbono orgânico e seus compartimentos em Argissolo sob floresta e sob milho cultivado com adubação mineral e orgânica. Revista Brasileira de Ciência do Solo, Viçosa, v.27, n.5, p.821-832, 2003.

LIMA, H. J. M.; OLIVEIRA, F. N. S.; CAJAZEIRA, J. P. Documentos 89 - Uso da Compostagem em Sistemas Agrícolas Orgânicos. Fortaleza, CE. Embrapa, Dezembro/2004. p. 09-16.

LOSS, A.; PEREIRA, M. G.; SCHULTZ, N.; DOS ANJOS, H. C.; SILVA, E. M. R. Frações orgânicas e índice de manejo de carbono do solo em diferentes sistemas de produção orgânica. Idesia, v.29, n.2, 2011.

LUCHESE, E. B. et al. Fase sólida do solo. In: Fundamentos da química do solo. Rio de Janeiro: Freitas Bastos, 2002. cap. 2, p. 19-45.

MELLEK, J. E.; DIECKOW, J., SILVA, V. L.; FAVARETTO, N.; PAULETTI, V.; VEZZANI, F. M.; SOUZA, J. L. M. Dairy liquid manure and no-tillage: physicl and hydraulic properties and carbon stocks in a cambisol of Southern Brazil. Soil \& Tillage Research. v. 110, n. 1, 2010. Disponível em: < http://dx.doi.org/10.1016/i.still.2010.06.005> 
MELO, A. V.; GALVÃO, J. C. C.; BRAUN, H., SANTOS, M. M.; COIMBRA, R.R.; SILVA, R. R.; REIS, W. F. Extração de nutrientes e produção de biomassa de aveiapreta cultivada em solo submetido a dezoito anos de adubação orgânica e mineral. Semina, v.32, n.2, p. 411-420, 2011.

MONTEZANO, E. M.; PEIL, R. M. N. Sistemas de consórcio na produção de hortaliças. R. Bras. Agrociência, Pelotas, v. 12, n. 2, p. 129 -132, abr-jun, 2006.

PEIXOTO FILHO, José U. et al . Produtividade de alface com doses de esterco de frango, bovino e ovino em cultivos sucessivos. Rev. bras. eng. agríc. ambient., Campina Grande, v. 17, n. 4, p. 419-424, Apr. 2013.

RAIJ, B. van; CANTARELLA, H.; QUAGGIO, J.A.; FURLANI, A.M.C. Recomendações de Adubação e Calagem para o Estado de São Paulo, 2 ed. rev. ampl. Campinas, Instituto Agronômico \& Fundação IAC, 1997. 285p. (Boletim Técnico, 100)

SOUZA, Pahlevi A. de et al. Características químicas de folhas de alface cultivada sob efeito residual da adubação com composto orgânico. Horticultura Brasileira, Brasília, v. 23, n. 3, p.754757, set. 2005. https://doi.org/10.1590/S0102-05362005000300013

SOUZA, J. L. de; RESENDE, P. Manual de horticultura orgânica. Viçosa, MG: Aprenda Fácil, 2006. $842 \mathrm{p}$.

SILVA, E. M. N. C. P.; FERREIRA, R. L. F.; ARAÚJO NETO S. E.;TAVELLA, L. B.; SOLINO, A. J. S. Qualidade de alface crespa cultivada em sistema orgânico, convencional e hidropônico. Horticultura Brasileira, v.29, p.242-245, 2011. https://doi.org/10.1590/S0102$\underline{05362011000200019}$

SILVA, F. de A. S. Assistat Software - Assistência Estatística. Versão 7.6 beta (2011). Disponível em http://www.assistat.com/indexp.html.

VAN DUYN, M.A.S.; PIVONKA, E. Overview of the health benefi ts of fruit and vegetable consumption for the dietetics professional: selected literature. Journal of The American Dietetic Association, 2000. v. 100, n.12, 10 p. 